\title{
The modification of the typhoon rainfall climatology model in Taiwan
}

\author{
C.-S. Lee ${ }^{1,2}$, L.-R. Huang ${ }^{1,2}$, and D. Y.-C. Chen ${ }^{1}$ \\ ${ }^{1}$ Taiwan Typhoon and Flood Research Institute, National Applied Research Laboratories, Taiwan \\ ${ }^{2}$ Department of Atmospheric Sciences, National Taiwan University, Taipei, Taiwan
}

Correspondence to: D. Y.-C. Chen (deliachen@ttfri.narl.org.tw)

Received: 30 March 2012 - Revised: 14 November 2012 - Accepted: 27 November 2012 - Published: 18 January 2013

\begin{abstract}
This study is focused on the modification of a typhoon rainfall climatological model, by using the dataset up to 2006 and including data collected from rain gauge stations established after the 921 earthquake (1999). Subsequently, the climatology rainfall models for westward- and northward-moving typhoons are established by using the typhoon track classification from the Central Weather Bureau. These models are also evaluated and examined using dependent cases collected between 1989 and 2006 and independent cases collected from 2007 to 2011. For the dependent cases, the average total rainfall at all rain gauge stations forecasted using the climatology rainfall models for westward- (WTRCM12) and northward-moving (N-TRCM12) typhoons is superior to that obtained using the original climatological model (TRCM06). Model W-TRCM12 significantly improves the precipitation underestimation of model TRCM06. The independent cases show that model W-TRCM12 provides better accumulated rainfall forecasts and distributions than model TRCM06. A climatological model for accompanied northeastern monsoons (A-TRCM12) for special typhoon types has also been established. The current ATRCM12 model only contains five historical cases and various typhoon combinations can cause precipitation in different regions. Therefore, precipitation is likely to be significantly overestimated and high false alarm ratios are likely to occur in specific regions. For example, model A-TRCM12 significantly overestimates the rainfall forecast for Typhoon Mitag, an independent case from 2007. However, it has a higher probability of detection than model TRCM06. From a disaster prevention perspective, a high probability of detection is much more important than a high false alarm ratio. The modified models can contribute significantly to operational forecast.
\end{abstract}

\section{Introduction}

The island of Taiwan is situated on one of the main western North Pacific typhoon paths. Significant changes often occur to typhoon structures as they cross the island. One of the biggest challenges to numerical weather prediction is quantitative precipitation forecasting (QPF), especially the forecasting of orographically induced heavy precipitation. Taiwan has recently experienced increasingly damaging typhoons (Emanuel, 2005; Liu et al., 2009). To reduce damage from typhoons, torrential rain, and floods, appropriate methods must be adopted in addition to currently available engineering solutions. Thus, QPF is important for non-structural damage mitigation methods. From a disaster reduction perspective, the threat of severe rainfall over a short period is the same as that of continuous rainfall. Taiwan is a small island approximately $140 \mathrm{~km}$ wide and $394 \mathrm{~km}$ long. The average elevation of the Central Mountain Range (CMR) exceeds $2000 \mathrm{~m}$ (Yushan Main Peak is $3952 \mathrm{~m}$ ). The CMR reduces the intensity of direct typhoon damage and creates favorable conditions for the orographic lifting mechanism (Chiao and Lin, 2003). This mountainous terrain provides an extremely strong terrain-blocking effect.

Previous studies (Wang et al., 1992; Chang et al., 1993; Lin et al., 2001) have identified several key factors that influence rainfall distribution during the typhoon season in Taiwan. These factors include typhoon structure (including typhoon circulation size, eyewall, and spiral rainbands), typhoon translation speed, environmental flow characteristics (for example, Asian summer southwesterly and northeasterly monsoons), and terrain-induced rainfall. Although recent studies have shown that many high-resolution dynamic models can simulate rainfall patterns in Taiwan, their forecast 
Table 1. The abbreviation for the models.

\begin{tabular}{ll}
\hline Acronym & Model description \\
\hline TRCM06 & Taiwan Typhoon Rainfall Climatology Model; Lee et al. (2006) \\
W-TRCM12 & The modified model for the westward moving typhoons \\
N-TRCM12 & The modified model for the northward moving typhoons \\
A-TRCM12 & The modified model for the typhoon accompanied with the northeasterly monsoon \\
\hline
\end{tabular}

accuracy varies, significantly reducing the value of the models for real-time applications.

The tools used to provide 0- to 24-h QPF include numerical model, climatology rainfall model, and the persistence method. Because of the time delay for model simulation, numerical products for real-time forecasts are only available for 9- to 24-h forecasts, whereas climatology rainfall model can provide rainfall predictions at short lead times and require fewer computations. Based on the assumption that rainfall is highly related to typhoon central position, climatology rainfall model can be developed using historical typhoon track and observation rainfall data (Chang et al., 1993).

For the previous climatological model, Lee et al. (2006) (acronym as TRCM06, Table 1) used typhoon track data from 1989 to 2002 obtained from the Central Weather Bureau (CWB) and hourly precipitation data collected from 371 rain gauge stations. Lee et al. (2006) used this data to calculate the mean, maximum, and standard deviation of hourly precipitation, how frequently hourly precipitation exceeded $15 \mathrm{~mm}$ and $50 \mathrm{~mm}$, and how often a typhoon passed each of the $0.5 \times 0.5^{\circ}$ grids between $118-126^{\circ} \mathrm{E}$ and $19-27^{\circ} \mathrm{N}$ of the 61 typhoons that hit Taiwan over the years. Using Barnes objective analysis, average precipitation data were interpolated into $0.1 \times 0.1^{\circ}$ grids to obtain a set of grid data with spatially uniform distributions for forecasting typhoon rainfalls. Basic assumptions were that the rainfall in a given area was affected by the distance from that area to the center of typhoon and by the direction of the typhoon (Chang et al., 1993). Therefore, combined with hourly precipitation data from a specific station, historical typhoon paths data can be used to create typhoon precipitation distribution maps for that station. For applications, the predicted path of a typhoon is adopted with the rainfall distribution map acquired from a specific station to provide a QPF for that station during a typhoon landfall. The climatological model captures rainfall enhancement details associated with the complex terrain.

Lee et al. (2006) and Cheung et al. (2008) evaluated TRCM06. Their results showed that the model captures rainfall patterns during a typhoon period, but often underestimates rainfall amount, which is an essential feature of the climatology model. The development of the TRCM06 was based on all the typhoon cases available in the database. Thus, the unique rainfall patterns associated with westward and northward moving storms were mixed, resulting in less than ideal rainfall statistics; the rainfall amount was therefore underestimated. To modify the model, this study divides the climatology model results according to typhoon tracks (westward or northward moving track) or environment (accompanied by a northeasterly monsoon). This study uses the same model setup as Lee et al. (2006) and Cheung et al. (2008), but uses more recent data (updated to 2006).

This paper is organized as follows: Sect. 2 explains the data quality control process; Sect. 3 describes the development of the typhoon rainfall climatology model; Sect. 4 discusses the results; and Sect. 5 presents a summary of the study.

\section{Data}

Typhoon track and rain gauge data are used to develop the model. The position of each typhoon at 3-h intervals is obtained from official reports of the CWB of Taiwan. The Akima interpolation scheme is used to interpolate the 3-h track data to obtain the hourly positions. Based on previous studies (Lee et al., 2006), the rain gauge data is updated to 2006 and new rain gauge stations are included (408 stations in total). The number of historical typhoon cases in the developmental database increased to 92 .

When heavy rain occurs, observational data may not be returned in real-time because of transmission problems. These unreturned data were then automatically grouped into the next dataset, and labeled with a special code to indicate transmission failure. Although these data reflect incorrect hourly rainfall, the accumulated rain gauge data are correct; therefore, accumulated rain gauge data are still applicable. Depending on the extent of the missing data, interpolation can be used to reconstruct data for quality control. To achieve this, select the rain gauge stations near a station where intensive precipitation records are observed. The stations should exhibit similar terrain features (such as plains, windward slopes, and river valleys). Once stations with similar properties have been selected, the rainfall amount weighting for the missing data period can be reconstituted by calculating the average value of the selected stations. Interpolation and data reconstruction can then be performed to recover missing data. If too much data are missing, data cannot be reconstructed. For example, data cannot be reconstructed if more than 24-h of data are missing, if data from nearby stations are insufficient or problematic, or if no representative stations with similar features exist. 


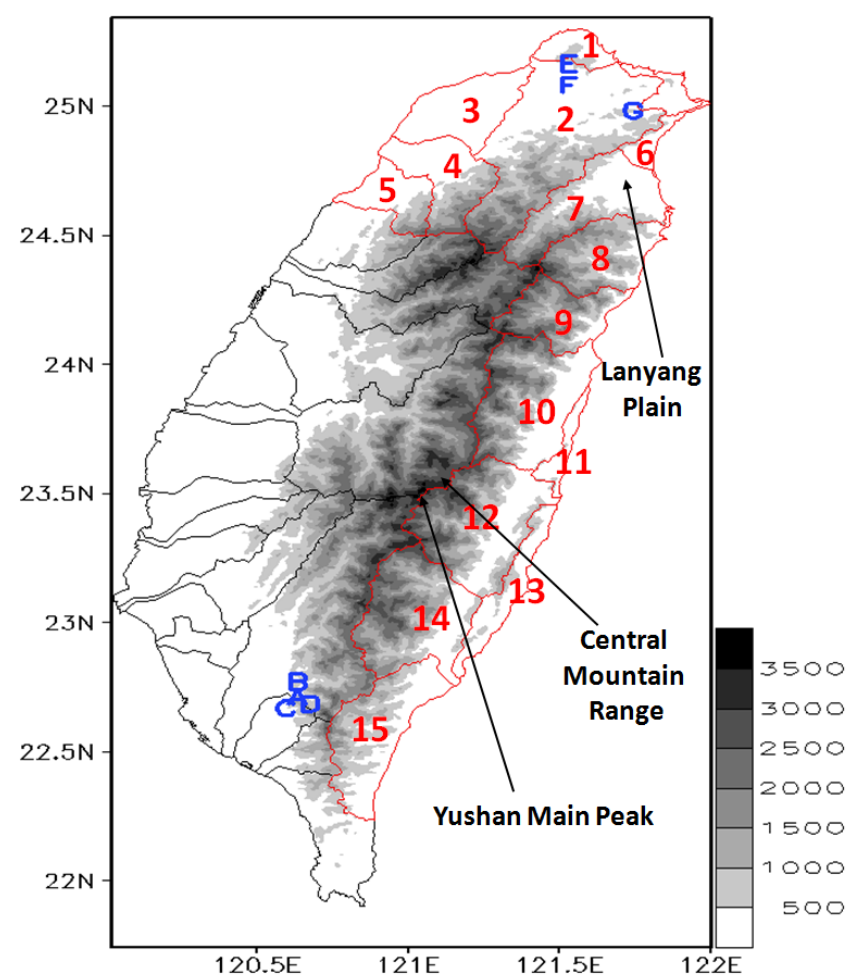

Fig. 1. Topography ( $m$, gray shading), river basins (region in black with red line) and the stations $(\mathrm{A}-\mathrm{G})$. The basins selected for the accompanied climatological rainfall model are (1) river basins of the northern coast, (2) Danshui River basin, (3) river basins along the Taoyuan coast, (4) Toucian River basin, (5) river basins along the Zhunan coast, (6) river basins along the Toucheng coast, (7) Lanyang river basin, (8) river basins along the Nanao coast, (9) river basins around Taroko, (10) Hualien river basin, (11) river basins along the Fengbin coast, (12) Siouguluan river basin, (13) river basins of east of the coastal mountains, (14) Beinan river basin and (15) river basins of the southern Taitung river. The stations are (A) Sandimen (C0R15), (B) Guxia (C1R11), (C) LongCyuan (C1R20), (D) Majia (C1R14), (E) Zhuzihu (01A42), (F) Wudu (01B03), (G) Huoshaoliao.

This section describes an actual quality control process. When Typhoon Haitang hit Taiwan in 2005, the automatic rain gauge station (COR15) in Sandimen (Fig. 1 Station A) recorded eight instances of missing data records within $12 \mathrm{~h}$ from 23:00 LST, 18 July. The observed hourly precipitations were $124.0 \mathrm{~mm}, 17.5 \mathrm{~mm}$, and $113.5 \mathrm{~mm}$ at 04:00, 07:00 and 09:00 on 19 July, respectively. The original data indicated that the precipitation record at 04:00 on 19 July reflected precipitation which had accumulated over $6 \mathrm{~h}$ (transmission of the five previous hourly precipitation values had failed) and precipitation records at 07:00 and 09:00 reflected precipitation which had accumulated over $3 \mathrm{~h}$ and $2 \mathrm{~h}$, respectively. Therefore, data collected from nearby stations with similar terrain features are used for weighting to reconstruct data through interpolation. Time-dependent

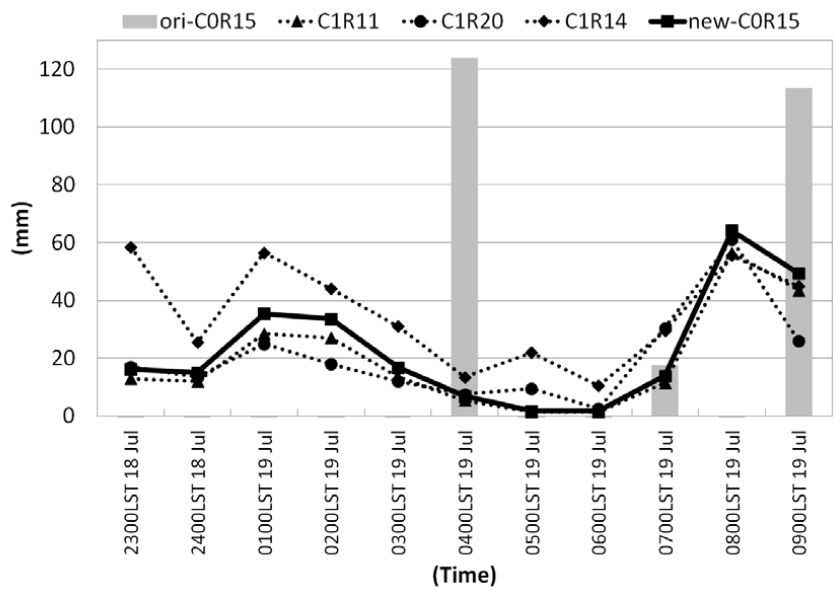

Fig. 2. Rainfall data collected by the Sandimen (COR15), Guxia (C1R11), Long-Cyuan (C1R20), and Majia (C1R14) stations between 23:00 LST, 18 July and 09:00 LST, 19 July.

precipitation data (Fig. 2) were collected from three stations near Sandimen station: Guxia (C1R11, Station B in Fig. 1), Long-Cyuan (C1R20, Station C), and Majia (C1R14, Station D). The results indicate that Guxia and Long-Cyuan stations had similar precipitation distributions during the same time intervals, but Majia station recorded heavier precipitation, which was probably caused by topographical factors. Data collected at the Guxia station are selected as the weighting standard because it has a geographical environment similar to that of Sandimen. Figure 2 shows the precipitation backstepping results.

\section{Methodology}

\subsection{Model description}

This study used a model domain between $19-27^{\circ} \mathrm{N}, 118$ $126^{\circ} \mathrm{E}$ with $0.5 \times 0.5^{\circ}$ grid. Typhoon track data are categorized into each grid box. Therefore, for a given rain gauge station, the average value, maximum value, and standard deviation of rainfall data for a typhoon passing over a certain grid box can be calculated. The interpolation scheme developed by Barnes (1973) (radius of influence: $200 \mathrm{~km}$ and convergence parameter: 0.3 ) is used to increase the grid resolution from $0.5 \times 0.5^{\circ}$ to $0.1 \times 0.1^{\circ}$ (approximately $11 \mathrm{~km}$ ). Thus, a rainfall climatology map is obtained for each rain gauge station. In real-time applications, the forecast track (official data issued by the CWB) is interpolated into hourly positions. The hourly rainfall data for each station are obtained from the rainfall climatology map. Rainfall data along the forecast track are accumulated to calculate 3-h, 6-h, or daily rainfall.

Estimating typhoon precipitation using existing climatological statistical models provides a general understanding of typhoon precipitation distributions. Figure 3 shows the 

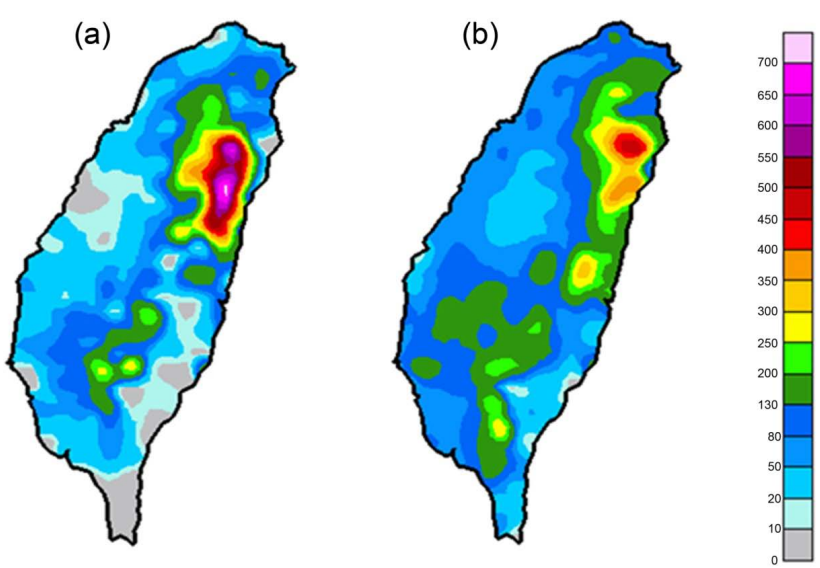

Fig. 3. The accumulated rainfall for Typhoon Longwang: (a) observed (05:30 LST, 1 October-08:30 LST, 3 October); and (b) the rainfall distribution estimated using TRCM06.

distribution of observed rainfall (Fig. 3a) and the rainfall estimated using TRCM06 (Fig. 3b) during the land warning period for Typhoon Longwang. As shown in Fig. 3, TRCM06 estimates the general northeastern and southern mountainous locations where heavy rainfall may occur, however, minor differences exist between local regional precipitation and distribution. Model TRCM06 cannot provide estimations on special typhoon types, such as typhoons accompanied by northeastern monsoons or southwestern monsoons. Therefore, climatological models for special typhoon types, conceptual models that use advanced observation techniques (e.g. satellite and radar) and dynamic simulation must be established to improve model application.

All typhoon cases are classified according to their movement direction and climatological rainfall models are established for westward- and northward-moving typhoons. Westward- and northward-moving typhoons are defined according to the typhoon tracks classification published by the CWB. Based on these definitions, 35 of the 92 typhoons that hit Taiwan between 1989 and 2006 are classified as westward-moving typhoons and 34 are classified as northward-moving typhoons. The selected typhoons are used to establish climatological rainfall models for westward- (WTRCM12) and northward-moving (N-TRCM12) typhoons. A special climatological rainfall model is also developed for accompanied cases that interact with the environment (ATRCM12). Previous studies (Chu and Chen, 1988; Chou et al., 2001; Lee et al., 2007; Wu et al., 2009) have shown that typhoons accompanied by northeastern monsoons are likely to cause more rainfall in northern and eastern Taiwan. During autumn or early winter, the typhoon outer core circulation interacts with the monsoonal northeasterlies and creates a frontal-type system. Because of the terrain blocking effect, the accompanied system brings enormous rainfall to certain areas in northern or eastern Taiwan. These typhoon centers are often quite far away from the enhanced rainfall area. Results show that from 1987 to 2011, eight typhoons (their centers are located in the selected domain) interacted significantly with the northeastern monsoon. A typical example of this scenario is Typhoon Lynn (Lee et al., 2007). Typhoon Lynn moved westward and turned northwestward, when the typhoon passed through northern Luzon Island; a cold front also occurred in northern Taiwan. Lee et al. (2007) analyzed the rainfall accompanying these types of typhoons and found that in addition to the accompanied effects of typhoon circulation and northeastern monsoons, the terrainlifting effect still produced huge rainfall. For example, considering Typhoon Zeb, which brought heavy rain to northern Taiwan in 1998, in addition to the mid-latitude trough, some of the rainfall could have been caused by the typhoon circulation; terrain also played a crucial role in the heavy rainfall (Chou et al., 2001). The accompanied effects of the interaction between outer-core circulations and large-scale flow can also cause heavy rain, even if the typhoon center is located far from northern Taiwan (a distance of greater than approximately 400-500 km) (Lee et al., 2007). Chu and Chen (1988) analyzed the precipitation features of six typhoons accompanied by northeastern monsoons and found that these types of typhoons are likely to form three major rainfall centers in northern Taiwan: the Datun mountainous areas (Zhuzihu, Station E in Fig. 1); the area between Wudu (Station F) and Huoshaoliao (Station G); and the western mountainous areas of the Lanyang Plain. According to Wang (1970), rainfall distributions caused by these types of typhoons are different, because of various high-pressure locations and typhoon paths.

Therefore, a rainfall database is created for northern and eastern Taiwan (river basin indicated by the red line in Fig. 1) by considering the rainfall characteristics of typhoons accompanied by northeastern monsoons. Data from all the typhoons that hit Taiwan between 1989 and 2006 are still used for other basins. The available historical data (1989 to 2006) include five typhoons accompanied by northeastern monsoons. These five cases are selected to establish a climatological rainfall model for typhoons accompanied by northeastern monsoons (A-TRCM12).

To validate models W-TRCM12 and N-TRCM12, their rainfall patterns are assessed using dependent cases (19872006). In addition, the typhoons that hit Taiwan in 2007 2011 are used as independent cases. Table 2 shows the cases list and Fig. 4 shows the typhoon tracks. The 24-h rainfall forecasts for 408 rain gauge stations throughout Taiwan are compared with observed rainfall. To examine the ATRCM12 in more detail, Typhoons Mitag 2007, Parma 2009 and Megi 2010, are selected for independent cases evaluation and examination. Forecast rainfall from TRCM06 is also calculated and compared to forecasts from A_TRCM12. These forecasts are then validated using actual rainfall data to better understand how classifying typhoons according to their tracks or unique environmental effects improves climatological models. 
Table 2. The typhoon list for the independent cases.

\begin{tabular}{ll}
\hline Westward moving typhoons & $\begin{array}{l}\text { 2007 Pabuk, 2007 Wutip, 2007 Sepat, 2007 Wipha, 2007 Krosa, } \\
\text { 2008 Kalmaegi, 2008 Fung-wong, 2008 Sinlaku, 2008 Jangmi, } \\
\text { 2009 Morakot, } \\
\text { 2010 Namtheun, 2010 Fanapi, 2011 Nanmadol }\end{array}$ \\
& 2010 Lionrock, 2010 Meranti, 2010 Megi \\
$\begin{array}{l}\text { Northward moving typhoons } \\
\begin{array}{l}\text { The typhoon accompanied with } \\
\text { the northeasterly monsoon }\end{array}\end{array}$ \\
\hline
\end{tabular}

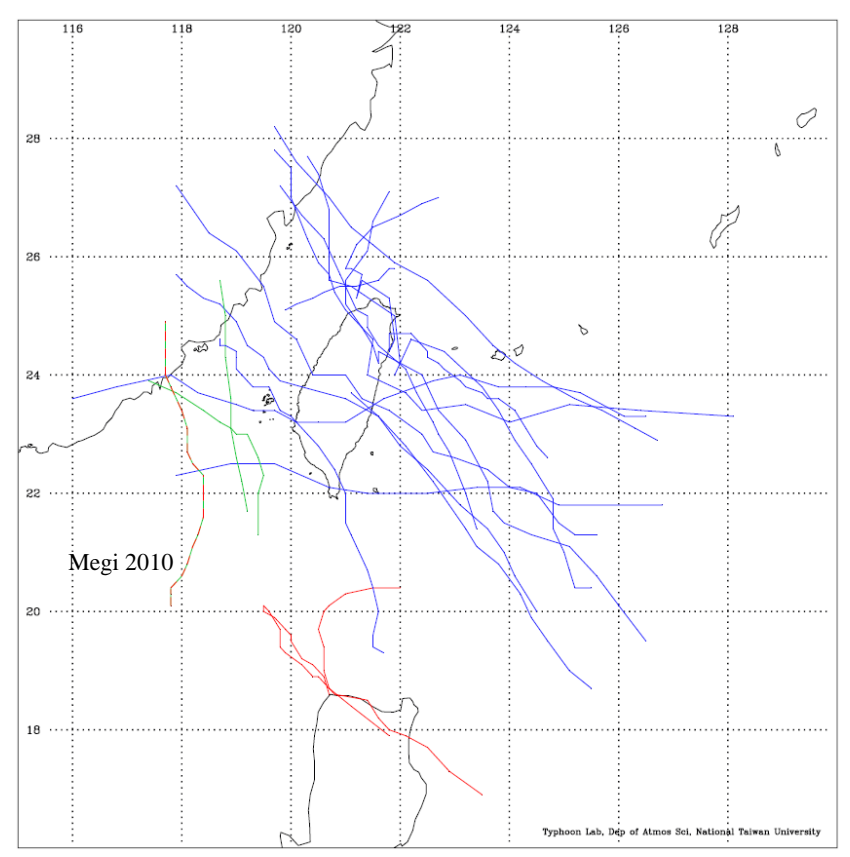

Fig. 4. The track for the independent cases. Blue lines: westward moving typhoon; green lines: northward moving typhoon; and red lines: the typhoon accompanied with the northeasterly monsoon.

\subsection{Verification method}

This study conducts a contingency table analysis to calculate rainfall forecast accuracy in order to evaluate the modified climatological rainfall models. The four combinations of forecasts (above or below the threshold) and observations (above or below the threshold), called joint distributions, are: hit: event forecast to occur and did occur, meaning that the forecasted rainfall at a given station is greater than the threshold value, and the observed rainfall at that station is also greater than the threshold value; miss: event forecast not to occur, but did occur; false alarm: event forecast to occur, but did not occur; and correct negative: event forecast not to occur, and did not occur. The rainfall rate definition established by the CWB is used to set the thresholds as follows: heavy rain: 24-h accumulated rainfall exceeds $50 \mathrm{~mm}$ with at least $1 \mathrm{~h}$ of $15 \mathrm{~mm}$ or above; extremely heavy rain: 24-h accumulated rainfall exceeds $130 \mathrm{~mm}$; torrential rain: 24-h accumulated rainfall exceeds $200 \mathrm{~mm}$; and extremely torrential rain: 24-h accumulated rainfall exceeds $350 \mathrm{~mm}$. The forecasted rainfalls are examined based on the contingency table by calculating five evaluation indices: the bias score (BS), probability of detection (POD), false alarm ratio (FAR), threat score (TS) and equitable threat score (ETS).

$$
\begin{aligned}
& \text { Bias }=\frac{\text { hits }+ \text { false alarms }}{\text { hits }+ \text { misses }} \\
& \mathrm{POD}=\frac{\text { hits }}{\text { hits }+ \text { misses }} \\
& \mathrm{FAR}=\frac{\text { false alarms }}{\text { hits }+ \text { false alarms }} \\
& \mathrm{TS}=\frac{\text { hits }}{\text { hits }+ \text { misses }+ \text { false alarms }}
\end{aligned}
$$

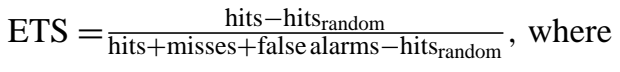

$$
\begin{aligned}
& \text { hits }_{\text {random }}=\frac{(\text { hits }+ \text { misses })(\text { hits }+ \text { false alarms })}{\text { total }}
\end{aligned}
$$

These analyses enable understanding of the typhoon rainfall forecasting performance of the climatological models at different rainfall thresholds.

Statistical parameters are also calculated to validate these models. The following statistical parameters are calculated (assuming that observed rainfall is $O_{i}$, forecasted rainfall is $F_{i}$, and the number of data points is $N$ ):

- Average Rainfall Rate: average rainfall rate for the observed and predicted rainfall at all rainfall gauge stations.

$$
\bar{O}=\frac{\sum_{i=1}^{N} O_{i}}{N}, \bar{F}=\frac{\sum_{i=1}^{N} F_{i}}{N}
$$

- Maximum Rainfall Rate: observed and predicted maximum rainfall.

- Mean Absolute Error

$$
\mathrm{MAE}=\frac{1}{N} \sum_{i=1}^{N}\left|F_{i}-O_{i}\right|
$$


- Root Mean Square Error

$$
\mathrm{RMSE}=\sqrt{\frac{1}{N} \sum_{i=1}^{N}\left(F_{i}-O_{i}\right)^{2}}
$$

- Correlation Coefficient

$$
r=\frac{\sum(F-\bar{F})(O-\bar{O})}{\sqrt{\sum(F-\bar{F})^{2}} \sqrt{\sum(O-\bar{O})^{2}}}
$$

The average and maximum rainfall rates mainly reflect the differences between the overall observed and forecasted rainfall values. The mean absolute error, root mean square error, and correlation coefficient mainly reflect the differences between the observed and forecasted rainfall distributions.

\section{Results}

\subsection{Westward- and northward-moving typhoons}

Figure 5 shows the forecasted rainfall accumulation (yaxis) compared to the observed rainfall accumulation ( $\mathrm{x}-$ axis) for all dependent case rain gauge stations using models TRCM06 and W-TRCM12. The validation results for accumulated rainfall indicate that the correlation coefficients of the forecasted and observed rainfall values for each station are 0.88 for TRCM06 and 0.92 for W-TRCM12. Using W-TRCM12 significantly reduces rainfall underestimation. Independent cases are also validated. Table 3 shows the validation results for various statistical parameters for rain gauge stations. Regarding average and maximum rainfall rates, W-TRCM12 is better than TRCM06 at estimating rainfall amount and at identifying rainfall distribution (the mean absolute error and correlation coefficient).

Table 4 shows the results of the forecasted precipitation scores with different threshold values for all rain gauge stations using contingency table analysis. Forecasts made using TRCM06 rapidly change from a slight underestimation ( $\mathrm{BS}=0.84$; threshold value $=50 \mathrm{~mm}$ ) to a severe underestimation $(\mathrm{BS}=0.07$; threshold value $=350 \mathrm{~mm}$ ) as the threshold value increases. By comparison, forecasts made using $\mathrm{W}$ TRCM12 change from a slight overestimation $(B S=1.01$; threshold value $=50 \mathrm{~mm})$ to an underestimation $(B S=0.36$; threshold value $=350 \mathrm{~mm}$ ). Regardless of threshold values, W-TRCM12 is better at POD than TRCM06. However, the FAR of W-TRCM12 is slightly greater than that of TRCM06. Model W-TRCM12 has a better TS and ETS than model TRCM06, particularly when the rainfall threshold is higher than $200 \mathrm{~mm}$ in 24-h. Therefore, the model performance validation results show that W-TRCM12 performs better than TRCM06 as the rainfall threshold increases. However, when the rainfall threshold increases to $350 \mathrm{~mm}$ in 24-h, both models perform poorly. The validation results using the
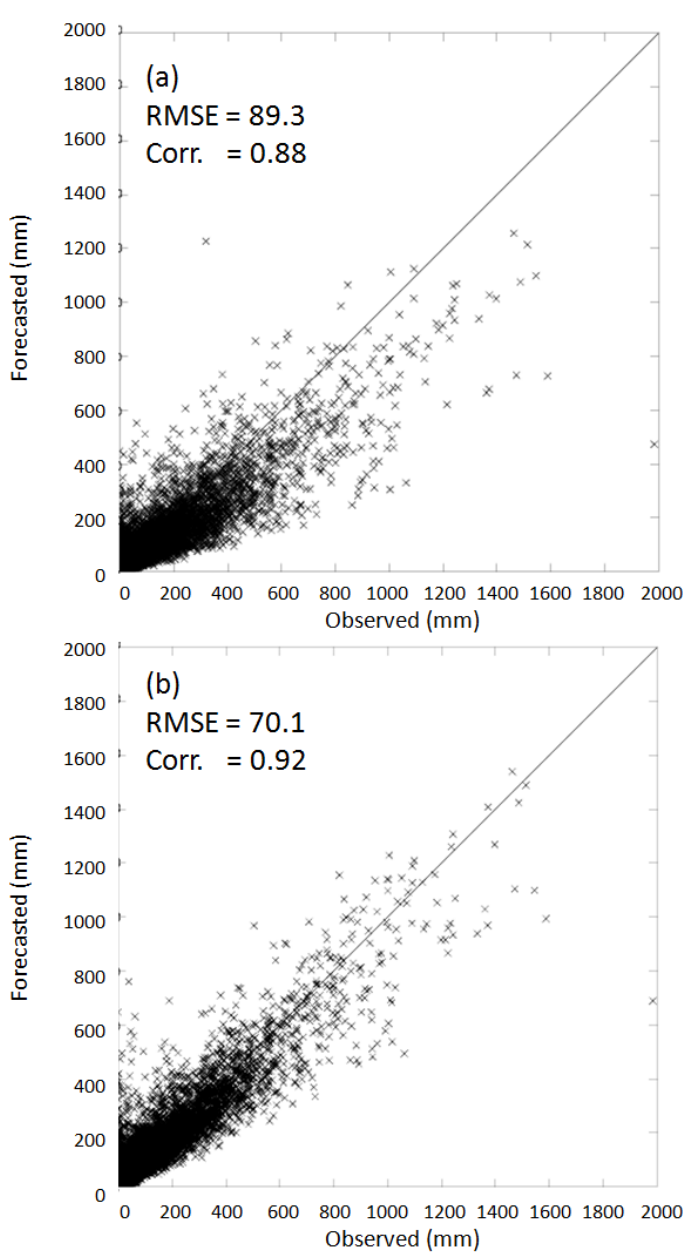

Fig. 5. The forecasted (y-axis) and observed (x-axis) rainfall accumulations of the dependent westward-moving typhoons (from 1989 to 2006) for all rain gauge stations: (a) TRCM06; and (b) WTRCM12.

independent cases show that W-TRCM12 performs better with heavier rains. However, this model also has a higher FAR than TRCM06.

Figure 6 shows the validation results for dependent northward-moving typhoons. Similar to W-TRCM12 results, $\mathrm{N}$-TRCM12 is better at forecasting the total rainfall amount at each dependent case rain gauge than TRCM06. However, it still underestimates the rainfall amount. The results of independent case validation show that the statistical parameters of TRCM06 are slightly better than model N-TRCM12 (Table 5). Comparing the contingency table analyses (Table 6) show that the performance difference between TRCM06 and N-TRCM12 is not significant. This may be because of the small sample of independent cases. The three independent cases are Typhoon Lionrock (2010), Meranti (2010) and Megi (2010). When Typhoon Lionrock affected Taiwan, Typhoon Namtheun was also located north of Taiwan. Lionrock moved northward for $6 \mathrm{~h}$ and then turned northwestward. 
Table 3. Validation results for the statistical parameters of independent westward-moving typhoons that hit Taiwan in $2007-2011$.

\begin{tabular}{|c|c|c|c|c|c|c|c|}
\hline & \multicolumn{2}{|c|}{$\begin{array}{c}\text { Average } \\
\text { Rainfall Rate }\end{array}$} & \multicolumn{2}{|c|}{$\begin{array}{l}\text { Maximum } \\
\text { Rainfall Rate }\end{array}$} & \multirow[t]{2}{*}{$\begin{array}{r}\text { Mean Absolute } \\
\text { Error }\end{array}$} & \multirow[t]{2}{*}{$\begin{array}{l}\text { Root Mean } \\
\text { Square Error }\end{array}$} & \multirow[t]{2}{*}{$\begin{array}{l}\text { Correlation } \\
\text { Coefficient }\end{array}$} \\
\hline & Model & Obs. & Model & Obs. & & & \\
\hline TRCM06 & 67 & \multirow{2}{*}{121} & 651 & \multirow{2}{*}{1673} & 79.4 & 136.6 & 0.59 \\
\hline W-TRCM12 & 96 & & 954 & & 72.2 & 120.8 & 0.65 \\
\hline
\end{tabular}

Table 4. Validation results for the statistical parameters of independent westward-moving typhoons that hit Taiwan in 2007-2011 using contingency table analysis.

\begin{tabular}{llrccc}
\hline \multirow{2}{*}{ Score } & & \multicolumn{4}{c}{ Criteria $\left(\mathrm{mm}^{-1}\right)$} \\
\cline { 3 - 6 } & Models & 50 & 130 & 200 & 350 \\
\hline \multirow{2}{*}{ BS } & TRCM06 & 0.84 & 0.51 & 0.30 & 0.07 \\
& W-TRCM12 & 1.01 & 0.85 & 0.69 & 0.36 \\
\multirow{2}{*}{ POD } & TRCM06 & 0.67 & 0.39 & 0.22 & 0.04 \\
& W-TRCM12 & 0.80 & 0.60 & 0.44 & 0.21 \\
\multirow{2}{*}{ FAR } & TRCM06 & 0.19 & 0.24 & 0.28 & 0.38 \\
& W-TRCM12 & 0.20 & 0.29 & 0.36 & 0.42 \\
\multirow{2}{*}{ TS } & TRCM06 & 0.58 & 0.34 & 0.20 & 0.04 \\
& W-TRCM12 & 0.67 & 0.48 & 0.35 & 0.18 \\
ETS & TRCM06 & 0.31 & 0.23 & 0.15 & 0.04 \\
& W-TRCM12 & 0.38 & 0.33 & 0.27 & 0.16 \\
\hline
\end{tabular}

Typhoon Meranti was generated in the ocean east of Taiwan and then moved southwestward, south of Taiwan. After passing $120^{\circ} \mathrm{E}$, Meranti turned northward. Typhoon Megi was on a northward-moving track and was also accompanied by the northeasterly monsoon. All three independent cases are atypical of northward-moving typhoons. Because of the limited database, the verification results show that N-TRCM12 is not better than TRCM06. Model N-TRCM12 should be verified using more comprehensive data.

\subsection{Typhoons accompanied by northeasterly monsoons}

Figure 7 shows the forecasted rainfall accumulation compared to that of the observed values for all dependent case rain gauge stations using TRCM06 and A-TRCM12. The results indicate that the correlation coefficients of the forecasts for each rain gauge station are 0.87 using TRCM06 and 0.95 using A-TRCM12. Model TRCM06 underestimates rainfall significantly more than model A-TRCM12. Model A-TRCM12 also produces a significantly lower root mean square.

Figure 8 shows the rainfall estimations for Typhoon Mitag from 14:00 LST, 26 November to 11:00 LST, 27 November, forecast using TRCM06 (Fig. 8b) and A-TRCM12 (Fig. 8c); Fig. 8a shows the observed rainfall amount. Results show that both models forecast the major rainfall area caused by Typhoon Mitag in eastern Taiwan. However, TRCM06
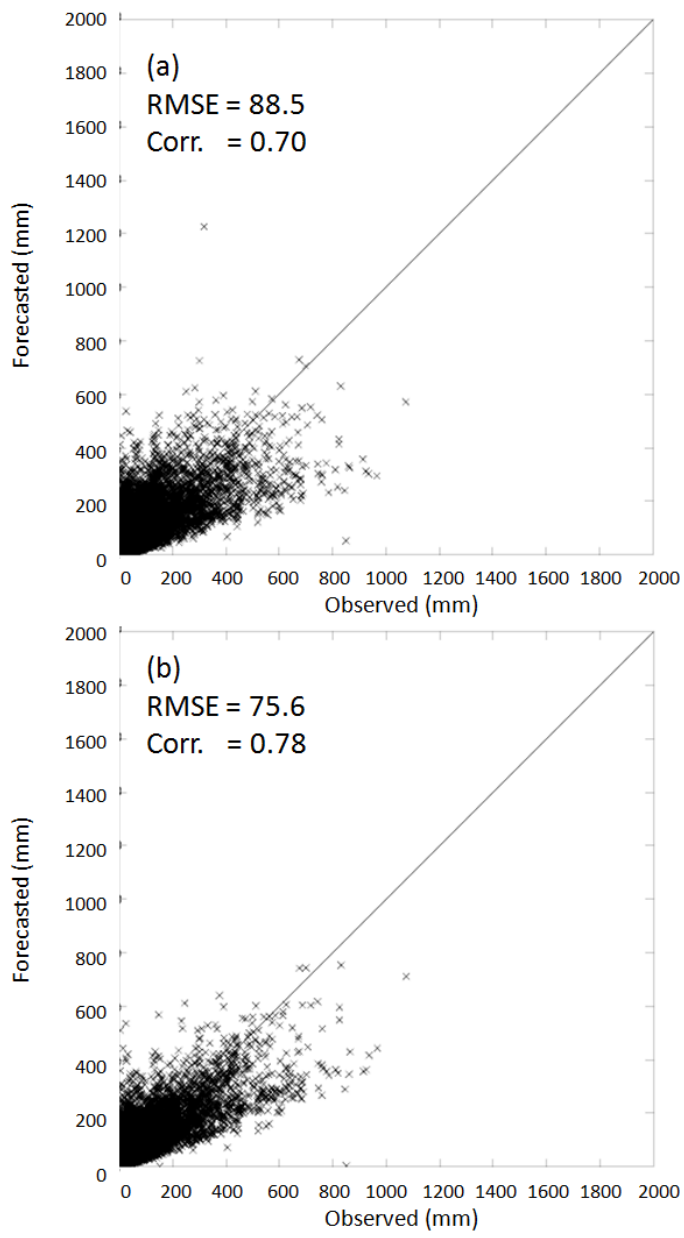

Fig. 6. The forecasted (y-axis) and observed (x-axis) rainfall accumulations of the dependent northward-moving typhoons (from 1989 to 2006) for all rain gauge stations: (a) TRCM06; and (b) $\mathrm{N}$ TRCM12.

underestimates the rainfall amount and A-TRCM12 significantly overestimates the rainfall amount caused by Typhoon Mitag in eastern Taiwan. Both models also underestimate the rainfall in western Taiwan.

Table 7 shows calculations for various statistical parameters at each rain gauge station. The results indicate that TRCM06 is better at forecasting average rainfall rates; the mean absolute error is smaller than A-TRCM12. 
Table 5. Validation results for the statistical parameters of independent northward-moving typhoons that hit Taiwan in $2007-2011$.

\begin{tabular}{|c|c|c|c|c|c|c|c|}
\hline & \multicolumn{2}{|c|}{$\begin{array}{c}\text { Average } \\
\text { Rainfall Rate }\end{array}$} & \multicolumn{2}{|c|}{$\begin{array}{l}\text { Maximum } \\
\text { Rainfall Rate }\end{array}$} & \multirow[t]{2}{*}{$\begin{array}{r}\text { MeanAbsolute } \\
\text { Error }\end{array}$} & \multirow[t]{2}{*}{$\begin{array}{l}\text { Root Mean } \\
\text { Square Error }\end{array}$} & \multirow[t]{2}{*}{$\begin{array}{c}\text { Correlation } \\
\text { Coefficient }\end{array}$} \\
\hline & Model & Obs. & Model & Obs. & & & \\
\hline TRCM06 & 30 & & 384 & & 28.1 & 48.1 & 0.31 \\
\hline N-TRCM12 & 27 & 28 & 266 & 437 & 27.0 & 46.3 & 0.27 \\
\hline
\end{tabular}
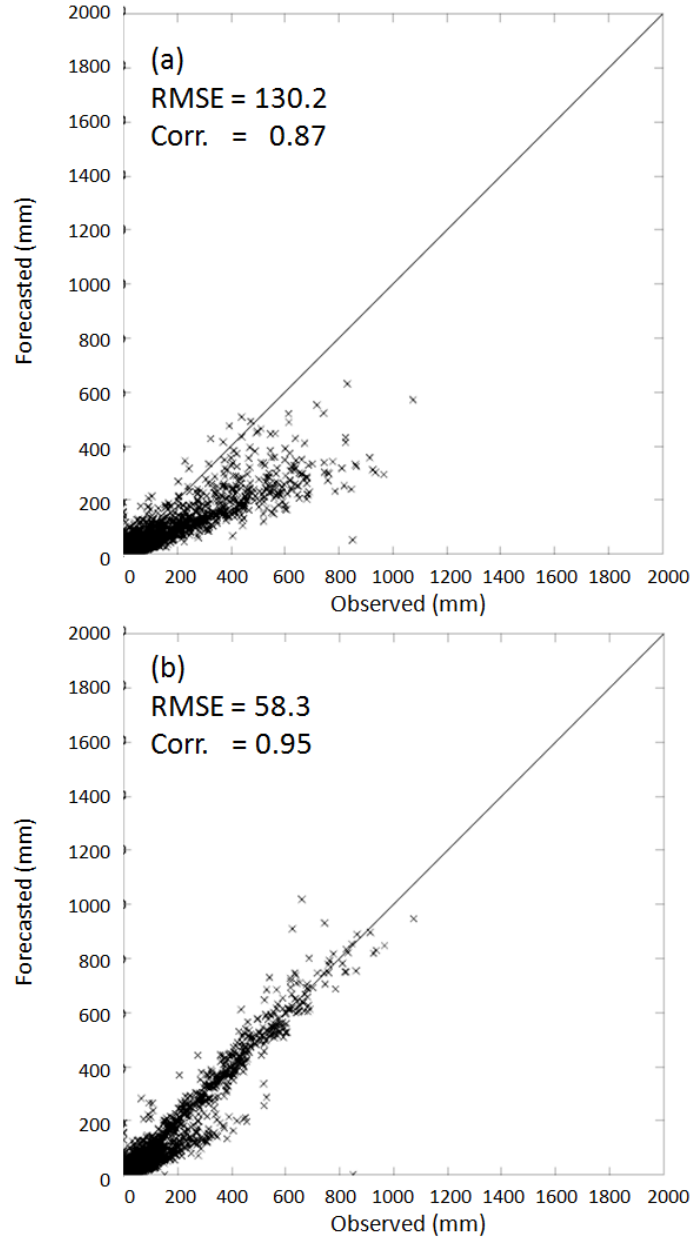

Fig. 7. The forecasted (y-axis) and observed (x-axis) rainfall accumulations of the dependent typhoons accompanied with northeastern monsoons (from 1989 to 2006) for all rain gauge stations: (a) TRCM06; and (b) A-TRCM12.

However, the maximum rainfall rate and correlation coefficient of A-TRCM12 is better than TRCM06. Table 8 shows the contingency table analysis results. Rainfall forecast using TRCM06 shifted from a slight underestimation $(\mathrm{BS}=0.73$; threshold value $=50 \mathrm{~mm})$ to a severe underestimation $(\mathrm{BS}=0.07$; threshold value $=350 \mathrm{~mm}$ ) when the threshold value increased. By contrast, A-TRCM12 overestimated rainfall regardless of threshold value. Estimated
Table 6. Validation results for the statistical parameters of independent northward-moving typhoons that hit Taiwan in 2007-2011 using contingency table analysis.

\begin{tabular}{llrrrr}
\hline & & \multicolumn{4}{c}{ Criteria $\left(\mathrm{mm} \mathrm{day}^{-1}\right)$} \\
\cline { 3 - 6 } Score & Models & 50 & 130 & 200 & 350 \\
\hline \multirow{2}{*}{ BS } & TRCM06 & 0.97 & 0.79 & 0.91 & 1.00 \\
& N-TRCM12 & 0.87 & 0.56 & 0.50 & - \\
\multirow{2}{*}{ POD } & TRCM06 & 0.38 & 0.12 & 0.07 & 0.00 \\
& N-TRCM12 & 0.33 & 0.11 & 0.05 & - \\
\multirow{2}{*}{ FAR } & TRCM06 & 0.61 & 0.84 & 0.93 & 1.00 \\
& N-TRCM12 & 0.62 & 0.80 & 0.91 & - \\
TS & TRCM06 & 0.24 & 0.07 & 0.03 & 0.00 \\
& N-TRCM12 & 0.22 & 0.07 & 0.03 & - \\
ETS & TRCM06 & 0.13 & 0.06 & 0.03 & 0.00 \\
& N-TRCM12 & 0.12 & 0.06 & 0.03 & - \\
\hline
\end{tabular}

(a)

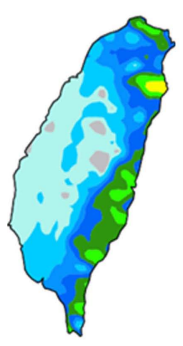

(b)

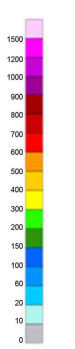

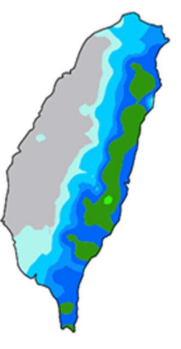

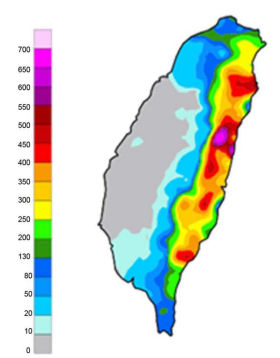

(c)

Fig. 8. The accumulated rainfall amount associated with Typhoon Mitag (2007) accumulated from 14:00 LST, 26 November, to 11:00 LST, 27 November: (a) observed; (b) the rainfall amount forecasted using the TRCM06; and (c) the rainfall amount forecasted using the A-TRCM12 (mm).

rainfall rapidly changed from a slight $(\mathrm{BS}=2.50$; threshold value $=50 \mathrm{~mm})$ to a severe overestimation $(B S=8.15$; threshold value $=350 \mathrm{~mm}$ ). Model A-TRCM12 performs better at POD than model TRCM06. However, A-TRCM12 also has a higher FAR than TRCM06 when the rainfall threshold is less than $130 \mathrm{~mm}$ in 24-h. Model TRCM06 has a better TS and ETS than model A-TRCM12 when the rainfall threshold is $50 \mathrm{~mm}$ in 24-h. For the three rainfall thresholds larger than $130 \mathrm{~mm}$ in 24-h, A-TRCM12 has a better TS and ETS than TRCM06. 
Table 7. Validation results for the statistical parameters of independent accompanied typhoons that hit Taiwan in 2007-2011.

\begin{tabular}{|c|c|c|c|c|c|c|c|}
\hline & \multicolumn{2}{|c|}{$\begin{array}{c}\text { Average } \\
\text { Rainfall Rate }\end{array}$} & \multicolumn{2}{|c|}{$\begin{array}{l}\text { Maximum } \\
\text { Rainfall Rate }\end{array}$} & \multirow[t]{2}{*}{$\begin{array}{r}\text { MeanAbsolute } \\
\text { Error }\end{array}$} & \multirow[t]{2}{*}{$\begin{array}{l}\text { Root Mean } \\
\text { Square Error }\end{array}$} & \multirow[t]{2}{*}{$\begin{array}{l}\text { Correlation } \\
\text { Coefficient }\end{array}$} \\
\hline & Model & Obs. & Model & Obs. & & & \\
\hline TRCM06 & 23 & & 408 & & 31.7 & 79.0 & 0.36 \\
\hline A-TRCM12 & 119 & 38 & 1745 & 1209 & 94.9 & 188.9 & 0.55 \\
\hline
\end{tabular}

Table 8. Validation results for the statistical parameters of independent accompanied typhoons that hit Taiwan in 2007-2011 using contingency table analysis.

\begin{tabular}{llrrrr}
\hline & & \multicolumn{4}{c}{ Criteria $\left(\mathrm{mm} \mathrm{day}^{-1}\right)$} \\
\cline { 3 - 6 } Score & Models & 50 & 130 & 200 & 350 \\
\hline \multirow{2}{*}{ BS } & TRCM06 & 0.73 & 0.32 & 0.14 & 0.07 \\
& A-TRCM12 & 2.50 & 2.85 & 3.76 & 8.15 \\
\multirow{2}{*}{ POD } & TRCM06 & 0.46 & 0.11 & 0.01 & 0.00 \\
& A-TRCM12 & 0.81 & 0.80 & 0.84 & 0.65 \\
FAR & TRCM06 & 0.37 & 0.67 & 0.90 & 1.00 \\
& A-TRCM12 & 0.67 & 0.72 & 0.78 & 0.92 \\
\multirow{2}{*}{ TS } & TRCM06 & 0.36 & 0.09 & 0.01 & 0.00 \\
& A-TRCM12 & 0.30 & 0.26 & 0.21 & 0.08 \\
ETS & TRCM06 & 0.28 & 0.07 & 0.00 & 0.00 \\
& A-TRCM12 & 0.14 & 0.20 & 0.18 & 0.07 \\
\hline
\end{tabular}

The validation results for the independent cases in 20072011 show that A-TRCM12 performs better with heavy rain, but the model also has a larger FAR. Model A-TRCM12 includes only five historical cases and typhoons accompanied by monsoons cause rainfall in different regions. Thus, severe overestimations and high FARs probably occur in certain regions. The accompanied effects of interaction between typhoon outer-core circulation and northeastern monsoons are usually restricted to a small region. Furthermore, the regions affected by the accompanied effects of various typhoons may differ. Hence, if A-TRCM12 is only used for forecasting, changes in the accompanied effects can lead to underestimating rainfall in regions affected by the accompanied effects, and overestimating rainfall in other regions. The various effects of typhoons accompanied by monsoons must be analyzed to identify the regions significantly affected by the accompanied effects to improve typhoon rainfall forecasts. Therefore, this model should be used cautiously.

\section{Summary and conclusion}

This study extends the climatological model developed by Lee et al. (2006) using an updated database to 2006 to increase model stability. All typhoons that affected Taiwan between 1989 and 2006 are also classified using the typhoon track classification created by the CWB to establish climatological rainfall models for westward- (WTRCM12) and northward-moving (N-TRCM12) typhoons. Five typhoons accompanied by monsoons are also selected to develop accompanied climatological rainfall models (ATRCM12). The dependent typhoons that occurred between 1989 and 2006 and the independent typhoons that occurred in 2007-2011 are used to validate established climatological rainfall models.

For the dependent cases, the results show that W-TRCM12 and N-TRCM12 perform better than TRCM06. Model WTRCM12 significantly improved rainfall underestimations by TRCM06. However, underestimations are still provided by N-TRCM12. The models are further validated using independent cases from 2007 to 2011 . The results indicate that W-TRCM12 is better at forecasting rainfall amount (average and maximum rainfall rates) and rainfall distribution (mean absolute error and correlation coefficients) than TRCM06. Contingency table analysis is used to calculate the accuracy of precipitation forecasts. The results indicate that model WTRCM12 provides better 24-h rainfall accumulation forecasts for rain gauge stations during heavy rain. However, this model also has a larger FAR than TRCM06. Due to the limited database for northward-moving cases, and because all independent cases are not typical northward-moving typhoons. The validation results between N-TRCM12 and TRCM06 are not significant. However, N-TRCM12 has potential for rainfall forecasting and future cases should be verified using N-TRCM12.

Model A-TRCM12 performs better for the dependent cases. The model significantly reduces rainfall underestimations of TRCM06. The model is further validated using independent cases from 2007 to 2011; the results indicate that the maximum rainfall rate and correlation coefficient of ATRCM12 are better than TRCM06. The precipitation score calculated using the contingency table shows that although A-TRCM12 performs better (higher POD) with heavy rain, it also has a larger FAR.

Substantial improvements to typhoon forecasting techniques are required, particularly for extreme rainfall, which cannot be managed using the TRCM06. A typhoon accompanied by a northeastern monsoon is an example of extreme rainfall type. Therefore, this study establishes climatological models for special typhoons (A-TRCM12) by integrating the historical data for typhoons with similar properties. Because special typhoons are rare and significant variations may exist, 
extensive analysis is required to obtain reliable results and variations between cases must be noted. The results of this study indicate that selecting similar types of typhoons can improve rainfall forecasting. For future study, the modification will be placed on river basins, and typhoons with similar properties (according to analogical concepts) will be used in order to forecast rainfall for various river basins using different rainfall thresholds. It is anticipated that this approach can compensate for the severe underestimations provided by TRCM06 and the high FARs of the special models.

Acknowledgements. Comments and suggestions from John Knaff and the other anonymous reviewer improved the manuscript substantially, and are much appreciated. We are grateful to the Data Bank for Atmospheric Project, Taiwan Typhoon and Flood Research Institute, National Applied Research Laboratories for their atmospheric research data. This research was supported by the National Science Council of the Republic of China (Taiwan) under Grants NSC 101-2625-M-492-001.

Edited by: A. Mugnai

Reviewed by: J. Knaff and one anonymous referee

\section{References}

Barnes, S. L.: Mesoscale objective analysis using weighted time-series observations, NOAA Tech. Memo. ERL NSSL62, National Severe Storms Lab., Norman OK 73069, 60 pp. [NTISCOM-73-10781], 1973.

Chang, C. P., Yeh, T. C., and Chen, J. M.: Effects of terrain on the surface structure of typhoons over Taiwan, Mon. Weather Rev., 121, 734-752, 1993.

Cheung, K. K. W., Huang, L.-R., and Lee, C.-S.: Characteristics of rainfall during tropical cyclone periods in Taiwan, Nat. Hazards Earth Syst. Sci., 8, 1463-1474, doi:10.5194/nhess-8-1463-2008, 2008.
Chiao, S. and Lin, Y. L.: Numerical modeling of an orographically enhanced precipitation event associated with tropical storm Rachel over Taiwan, Weather Forecast., 18, 325-344, 2003.

Chou, K.-H., Wu, C.-C., and Yen, T.-H.: The evolution of Typhoon Zeb in a non-hydrostatic mesoscale model, Atmos. Sci., 29, 291314, 2001 (in Chinese with an English abstract).

Chu, K.-K. and Chen, C.-K.: A study of heavy rainfall caused by typhoon Lynn, Atmos. Sci., 16, 253-262, 1988 (in Chinese with an English abstract).

Emanuel, K. A.,: Increasing destructiveness of tropical cyclones over the past 30 years, Nature, 436, 686-688, 2005.

Lee, C.-S., Huang, L.-R., Shen, H.-S., and Wang, S.-T.: A Climatology Model for Forecasting Typhoon Rainfall in Taiwan, Nat. Hazards, 37, 87-105, 2006.

Lee, C.-S., Luo, Y.-Z., and Chang, L.-Y.: A Study on the Heavy Rainfall Due to the Interactions of Typhoon Lynn (1987) and the Northeasterly Monsoon, Atmos. Sci., 35, 13-33, 2007 (in Chinese with an English abstract).

Lin, Y.-L., Sen, C., Wang, T.-A., Kaplan, M. L., and Weglarz, R. P.: Some Common Ingredients for Heavy Orographic Rainfall, Weather Forecast., 16, 633-660, 2001.

Liu, S. C., Fu, C., Shiu, C.-J., Chen, J.-P., and Wu, F.: Temperature dependence of global precipitation extremes, Geophys. Res. Lett., 36, L17702, doi:10.1029/2009GL040218, 2009.

Wang, S.-T.: On the synoptic features associated with three to six consecutive rainy days in Taiwan during cold season, Meteorol. Bull., 16, 18-31, 1970 (in Chinese with an English abstract).

Wang, S.-T.: An Integrated Study of the Impact of the Orography in Taiwan on the Movement, Intensity, Structure, Wind and Rainfall Distribution of Invading Typhoons, Technical Report 80-73, S\&T of the Multiple Hazards Mitigation Program, NSC, Taiwan, 285 pp., 1992 (in Chinese).

Wu, C.-C., Cheung, K. K. W., and Lo, Y.-Y.: Numerical study of the rainfall event due to the interaction of Typhoon Babs (1998) and the Northeasterly Monsoon, Mon. Weather Rev., 137, 20492064, 2009. 